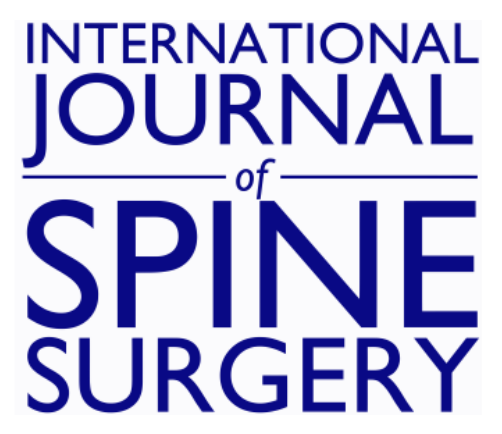

\title{
Soft Stabilization With an Artificial Intervertebral Ligament in Grade I Degenerative Spondylolisthesis: Comparison With Instrumented Posterior Lumbar Interbody Fusion
}

Chan Shik Shim, Sang-Ho Lee, Sun-Hee Park and Ji-Hee Whang

Int J Spine Surg 2007, 1 (3) 118-124

doi: https://doi.org/10.1016/SASJ-2006-0006-RR

http://ijssurgery.com/content/1/3/118

This information is current as of April 26, 2023.

Email Alerts Receive free email-alerts when new articles cite this article. Sign up at: http://ijssurgery.com/alerts 


\title{
Soft Stabilization With an Artificial Intervertebral Ligament in Grade I Degenerative Spondylolisthesis: Comparison With Instrumented Posterior Lumbar Interbody Fusion
}

Chan Shik Shim, MD, PhD, Sang-Ho Lee, MD, PhD, Sun-Hee Park, RN, CNS, and Ji-Hee Whang, MS

\begin{abstract}
Background

The purpose of this retrospective study was to evaluate the efficacy of soft stabilization with an artificial intervertebral ligament after microdecompression for the treatment of grade I degenerative spondylolisthesis.

Methods

From a total of 54 patients with degenerative spondylolisthesis who were treated surgically from May 2000 to April 2003, 36 patients who showed grade I spondylolisthesis without evidence of concomitant disc herniation necessitating discectomy were enrolled in the study. After decompression, the patients had undergone either soft stabilization with an artificial intervertebral ligament $(n=17)$ or instrumented posterior lumbar interbody fusion (PLIF; $n=19$ ).
\end{abstract}

Results

The average follow-up period was 24 months for the PLIF group and 16 months for the soft stabilization group. In the PLIF group, preoperative mean scores of $60 \%$ on the Oswestry Disability Index, 8.8 on the visual analog scale (VAS) for low-back pain, and 9.3 on the VAS for leg pain improved to $28 \%, 4.1$, and 2.6, respectively, after surgery. Corresponding scores in the soft stabilization group were $55 \%, 8.4$, and 8.9 , improving to $25 \%, 4.1$, and 2.2 after surgery. There were no significant differences between the 2 groups in any of these clinical parameters. Patients' subjective improvement rates and satisfaction with the surgical procedure were higher in the soft stabilization group, but the differences were not significant. Mean operation time and mean blood loss were significantly lower in the soft stabilization group than in the PLIF group. In the soft stabilization group, there were 3 cases of progression of slippage in patients who had had preoperative slippage of more than $20 \%$; there was 1 dural tear in the PLIF group.

Conclusions

Patients with grade I degenerative spondylolisthesis who received soft stabilization with an artificial intervertebral ligament after microdecompression had clinical outcomes similar to those of patients who received PLIF. Since soft stabilization can be done in a much less invasive way than fusion, if slippage is $20 \%$ or less, soft stabilization with an artificial ligament is a viable alternative to fusion for patients who are elderly or who have significant comorbidities that make a prolonged operation inadvisable.

Level of Evidence

This study was a retrospective comparative study with a very limited population (level III evidence).

Key words Spondylolisthesis, spinal stenosis, soft stabilization, ligamentoplasty, artificial intervertebral ligament, spine arthroplasty. SAS Journal. Summer 2007;1:118-124. DOI: SASJ-2006-0006-RR

\section{INTRODUCTION}

Surgical treatment of degenerative spondylolisthesis is controversial. Some investigators have proposed that simple decompressive surgery is enough for the patient with spinal stenosis caused by degenerative spondylolisthesis. ${ }^{1-4}$ Others insist that concomitant spinal arthrodesis should be added to decompression to prevent recurrence of symptoms and maximize functional outcome. ${ }^{5,6}$ Although some clinical studies have supported simple decompression in select groups of patients with degenerative spondylolisthesis, ${ }^{1,3,4,7}$ evidence that concomitant spinal arthrodesis enhances patients' clinical outcomes has been accumulating. ${ }^{5,8-14}$ Since the prospective randomized study of Herkowitz and Kurz ${ }^{5}$ and the meta-analysis of Mardjetko et al., ${ }^{15}$ the predominant - though not unanimous - opinion in the spinal community has been that additional spinal stabilization procedures may improve the surgical outcome of patients with degenerative spondylolisthesis. 
However, fusion has its own set of problems, including increased morbidity and mortality rates, donor-site pain, hardware-related problems such as screw malpositioning or failure, symptomatic pseudarthrosis, and accelerated degeneration of adjacent segments. ${ }^{16-20}$ Accelerated degeneration of adjacent segments has been a major concern because it can cause a deterioration of the initial success of fusion. In an effort to avoid fusion-related problems, researchers have introduced a number of artificial disc and nucleus devices for the treatment of degenerative disc disease and several soft spinal fixation methods for degenerative spinal instability. ${ }^{21-28}$

Since research has shown that decompression for spinal stenosis may cause postoperative spinal instability ${ }^{29}$ and that stabilization following neural decompression prevents further slippage, reduces recurrence of back and leg symptoms, and maximizes functional recovery, ${ }^{5,6,14}$ in our practice, patients with spinal stenosis caused by degenerative spondylolisthesis underwent a spinal stabilization procedure-either solid fusion or soft fixation - after neural decompression. For solid fixation of the spinal motion segment, we used instrumented posterior lumbar interbody fusion (PLIF); for soft fixation, we used ligamentoplasty with an artificial intervertebral ligament. This study was conducted to determine the clinical efficacy of ligamentoplasty with an artificial intervertebral ligament compared with instrumented PLIF in the treatment of spinal stenosis caused by grade I degenerative spondylolisthesis.

\section{MATERIALS AND METHODS}

\section{Patient Population}

From May 2000 to April 2003, a total of 54 patients with single-level degenerative spondylolisthesis at L4-L5 were treated surgically by a single surgeon (C.S.S.). The indication for surgery was the presence of refractory symptoms that did not respond to prolonged conservative care. Presenting symptoms were neurogenic intermittent claudication with low back and gluteal pain. After decompression, patients underwent either instrumented PLIF or soft stabilization with an artificial intervertebral ligament. The surgical procedure was chosen by the operating surgeon. However, PLIF was always chosen for patients with marked instability (olisthesis greater than 25\%) or with spondylolisthesis compounded by disc herniation that necessitated discectomy. To permit comparison of the 2 procedures among patients with similar clinical conditions, we excluded patients with olisthesis greater than $25 \%$ or with spondylolisthesis compounded by disc herniation. Therefore, 36 patients who showed grade I spondylolisthesis at L4-L5, who showed no evidence of concomitant disc herniation, and who were observed for more than 6 months were enrolled in the study; 19 were treated with PLIF and 17 with soft stabilization (Table 1). The mean follow-up period was 24 months (range, 6-39 months) in the PLIF group and 16 months (range, 6-39 months) in the soft stabilization group.
Table 1

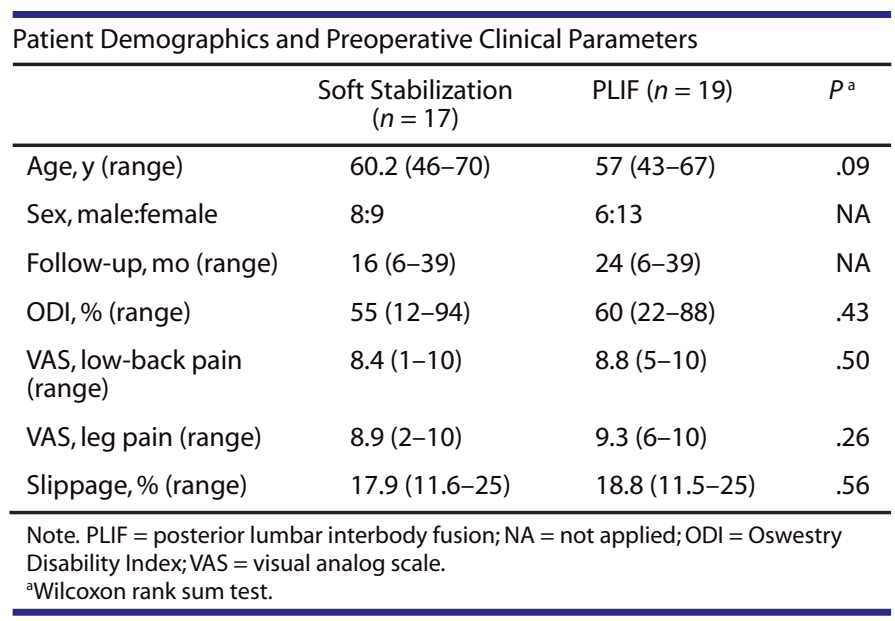

\section{Data}

We administered a preoperative questionnaire containing a 10-point visual analogue scale (VAS) for low-back pain and leg pain and the Oswestry Disability Index ${ }^{30}$ (ODI), and a postoperative questionnaire containing questions about subjective improvement and satisfaction with the surgery in addition to the VAS and ODI. The postoperative questionnaire was repeated at regular follow-ups of 3, 6, and 12 months and annually thereafter. Questionnaires administered at the last follow-up were included in the data analysis.

Plain X-rays including dynamic lateral views were taken at regular follow-ups. In the PLIF group, a thin-slice computerized tomography (CT) scan was done to assess fusion status at the 6-month follow-up. An independent clinical nurse specialist evaluated all radiological data. Preoperative and postoperative percentage of slippage was measured in the standing lateral view of a plain radiograph (Figure 1). Radiological fusion was assessed in the PLIF group by means of the criteria suggested by McAfee et al. ${ }^{31}$ : (1) the presence of bridging bone in the interbody space, (2) $5^{\circ}$ or less of measured motion on lateral dynamic radiographs, (3) the absence of radiolucencies in adjacent surfaces of the cages, and (4) thin-section, sagittal plane CT showing bone bridging from one vertebral body to the other.

Statistical analysis was done with the Wilcoxon rank-sum test, the Mann-Whitney test, and Fisher's exact test; $P$ of less than .05 was regarded as statistically significant.

\section{Artificial Intervertebral Ligament}

The artificial intervertebral ligament used, LVR (Ligament Vertebral de Renfort, Cousine Biotech, Wervicq-sud, France), is composed of a polyester of polyethylene terephthalate and a central thread of barium-platinum radiopaque silicone. Its main function is holding 2 or 3 consecutive spinous processes of vertebrae together tightly without complete abolishment of the movement between them (Figures 2 and 3). 


\section{Figure 1}

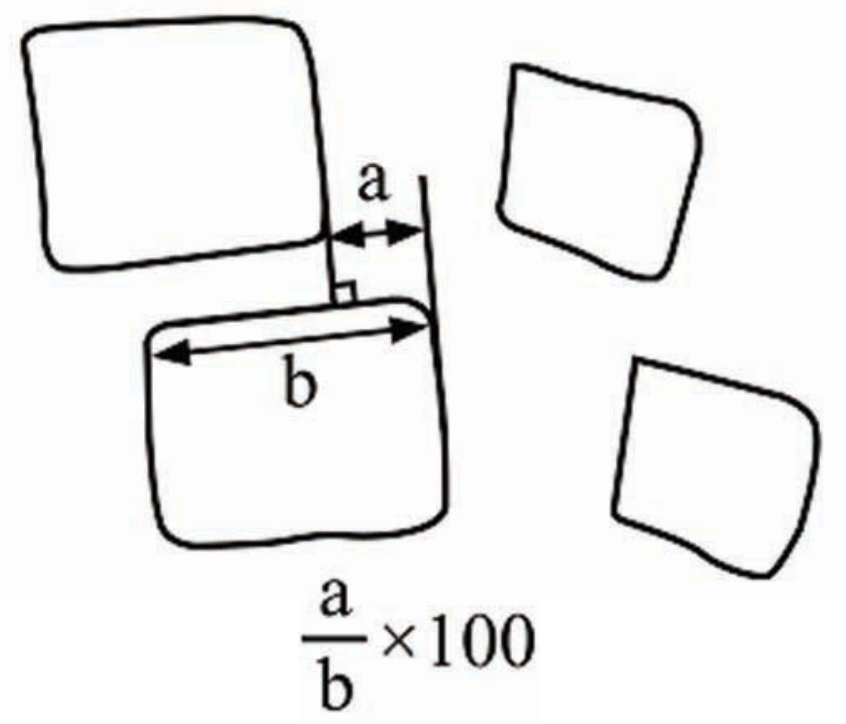

Diagram representing the radiographic measurement of slippage.

\section{Figure 2}

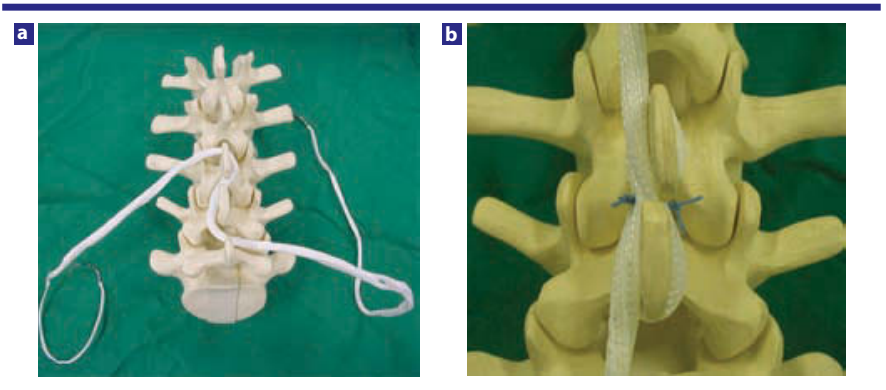

Intervertebral ligamentoplasty with an artificial ligament: (a) Artificial intervertebral ligament. (b) The ligament applied around the spinous processes of a spine model in a figure eight pattern. The crossing point of the ligament is sutured several times with nonabsorbable suture.

\section{Figure 3}

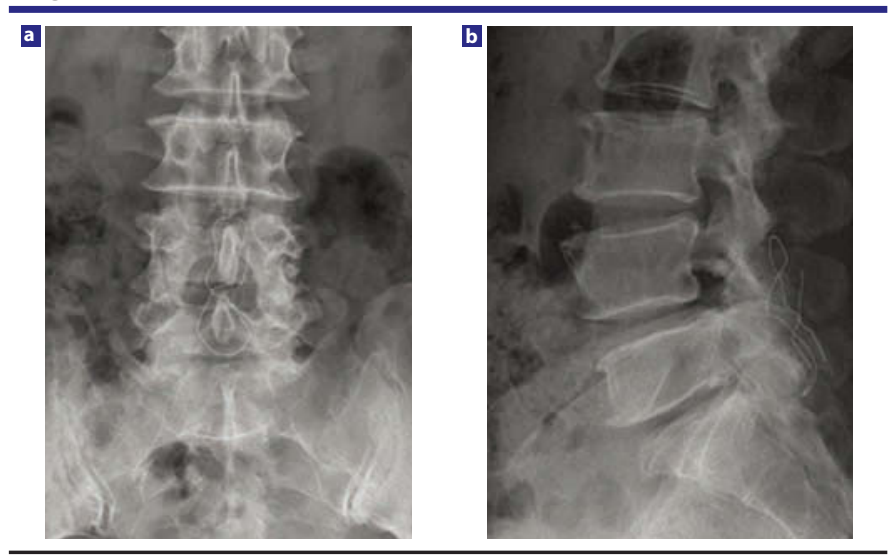

Postoperative anteroposterior view (a) and lateral view (b) of plain radiograph showing the artificial ligament applied around spinous processes. A radiopaque thread of barium-platinum cord makes the ligament visible in radiographs.
Operative Techniques

Microdecompression and Soft Stabilization

A midline skin incision and bilateral fascial incisions were made, sparing the supraspinatus ligament. Muscle was dissected and retracted laterally, exposing both laminae. Bilateral laminotomy was performed with a high-speed drill and the ligamenta flava and ventral portion of the interspinous ligament were removed. To decompress neural tissue at the lateral recess, the roof of the lateral recess was removed. After full decompression of the neural tissue, the operating table was positioned to provide lumbar extension. The artificial ligament was applied around the L4 and L5 spinous processes in a figure-eight pattern, and the crossing point of the ligament between spinous processes was sutured several times with nonabsorbable suture. The wound was closed in the usual way.

\section{PLIF}

A midline skin incision was made. After dissection and retraction of the fascia and muscle, bilateral total laminectomy and medial facetectomy were performed. In some cases where wide exposure was needed for the insertion of interbody cages, total facetectomy was done. Cage-assisted interbody fusion was done bilaterally. Local bone harvested from the laminectomy was used in the cages. Additional grafts were packed into the space between the cages or lateral to the cages. Pedicle screws were inserted and rods were attached and fixed. The wound was closed in the usual way.

\section{RESULTS}

The average age of the patients with soft stabilization was 60.2 years (range, 46-70 years); the average age of the PLIF group was 57 years (range, 43-67 years). There were 8 men and 9 women in the soft stabilization group and 6 men and 13 women in the PLIF group. There were no significant statistical differences between the 2 groups in preoperative parameters, including age, VAS for low-back pain, VAS for leg pain, ODI score, and vertebral slippage $(P>.05$; Table 1$)$. The mean ODI of the soft stabilization group improved from a preoperative score of $55 \%$ (range, $12 \%-94 \%$ ) to a postoperative score of $25 \%$ (range, 2\%-64\%; Tables 1 and 2). The mean ODI of the PLIF group showed similar improvement, from 60\% (range, $22 \%-88 \%$ ) to $28 \%$ (range, $2 \%-74 \%$ ). Mean VAS scores for low-back pain improved from 8.4 (range, 1-10) to 4.1 (range, 0-9) in the soft stabilization group and from 8.8 (range, 5-10) to 4.1 (range, 1-10) in the PLIF group. Mean VAS scores for leg pain improved from 8.9 (range, 2-10) to 2.2 (range, 0-7) in the soft stabilization group and from 9.3 (range, 6-10) to 2.6 (range, 0-10) in the PLIF group. There were no significant differences between the 2 groups in postoperative ODI, lowback pain VAS, and leg pain VAS scores $(P=.74, .84$, and .67, respectively) or in improvement of those 3 parameters $(P=.9$, .74 , and .85 , respectively, Mann-Whitney test; Table 2 ).

Subjective clinical improvement was better in the soft stabilization group (74.7\%) than in the PLIF group (69.9\%), 
Table 2

\begin{tabular}{|c|c|c|c|}
\hline \multicolumn{4}{|c|}{ Postoperative Clinical and Radiological Parameters } \\
\hline & $\begin{array}{l}\text { Soft Stabilization } \\
\qquad(n=17)\end{array}$ & $\begin{array}{l}\text { PLIF } \\
(n=19)\end{array}$ & $P$ a \\
\hline ODI, \% (range) & $25(2-64)$ & $28(2-74)$ & .74 \\
\hline VAS, back pain (range) & $4.1(0-9)$ & $4.1(1-10)$ & .84 \\
\hline VAS, leg pain (range) & $2.2(0-7)$ & $2.6(0-10)$ & .67 \\
\hline $\begin{array}{l}\text { Subjective improvement } \\
\text { rate, \% (range) }\end{array}$ & $74.7(50-100)$ & $69.9(0-80)$ & .96 \\
\hline $\begin{array}{l}\text { Operation time, } \min \\
\text { (range) }\end{array}$ & $101(60-180)$ & $216(135-495)$ & $<.05$ \\
\hline Blood loss, mL (range) & $261(150-450)$ & $827(450-1250)$ & $<.05$ \\
\hline Slippage, \% (range) & $17.6(8.2-29.6)$ & $4.2(0-17.6)$ & $<.01$ \\
\hline \multicolumn{4}{|c|}{$\begin{array}{l}\text { Note. PLIF = posterior lumbar interbody fusion; ODI = Oswestry Disability Index; } \\
\text { VAS = visual analog scale. } \\
\text { aWilcoxon rank sum test. }\end{array}$} \\
\hline
\end{tabular}

but the difference was not significant $(P=.96)$. Mean operation time and mean blood loss were significantly lower in the soft stabilization group than in the PLIF group (101 vs 216 minutes and $261 \mathrm{~mL}$ vs $827 \mathrm{~mL} ; P<.05)$. Eight patients in the PLIF group needed blood transfusions.

Although there was no statistical difference between preoperative and postoperative vertebral slippage in the soft stabilization group (preoperative mean $=17.9 \%$ [range, $11.6 \%-$ $25 \%$ ], postoperative mean $=17.6 \%$ [range, $8.2 \%-29.6 \%$ ]; $P=$ .29), vertebral slippage in the PLIF group was significantly reduced $(P<.01)$, from a preoperative mean of $18.8 \%$ (range, $11.5 \%-25 \%$ ) to a postoperative mean of $4.2 \%$ (range, $0 \%-$ $17.6 \%)$. Patients' satisfaction with the procedure was higher in the soft stabilization group $(94.1 \%)$ than in the PLIF group $(84.2 \%)$, but this difference was not statistically significant $(P$ $=.35$, Fisher's exact test; Table 3 ).

\section{Table 3}

\begin{tabular}{lccccc}
\hline \multicolumn{5}{l}{ Patients' Satisfaction With Surgical Procedure } \\
\hline Group & $n$ & $\begin{array}{c}\text { Very } \\
\text { Satisfied }\end{array}$ & Satisfied & Dissatisfied & $\begin{array}{c}\text { Very } \\
\text { Dissatisfied }\end{array}$ \\
\hline $\begin{array}{l}\text { Soft } \\
\text { stabilization }\end{array}$ & 17 & $4(23.5)$ & $12(70.6)$ & $1(5.9)$ & $0(0)$ \\
PLIF & 19 & $5(26.3)$ & $11(57.9)$ & $2(10.5)$ & $1(5.3)$ \\
Total & 36 & $9(25)$ & $23(63.9)$ & $3(8.3)$ & $1(2.8)$ \\
\hline
\end{tabular}

Note. PLIF = posterior lumbar interbody fusion.

Radiological fusion occurred in all PLIF patients. In the soft stabilization group, 3 of 4 patients who had had preoperative slippage of more than $20 \%$ showed progression of slippage after surgery. Even so, the clinical parameters of these patients showed improvement, and all of them were satisfied with the surgery. Among 13 patients with preoperative slippage of $20 \%$ or less, there was no progression of slippage. There was 1 case of dural tear in the PLIF group; it was repaired directly and the patient recovered without sequelae.

\section{DISCUSSION}

Despite continuing controversy and sporadic reports supporting simple decompression in certain groups of patients with degenerative spondylolisthesis, ${ }^{1-4,7}$ evidence has mounted over the last decade that decompression with fusion may improve outcomes compared with decompression alone..$^{5,8-14}$ However, spinal fusion has been criticized for its associated complications and morbidities, such as donor-site problems, hardware failure, and accelerated degeneration of adjacent segments. ${ }^{17-20}$ In addition, fusion in elderly patients with degenerative spondylolisthesis has been associated with higher morbidity. ${ }^{5,16}$ These problems led spine surgeons to seek alternative stabilization methods for patients with degenerative spinal instability, methods that would not increase morbidity and that could be done in a less invasive way.

Several investigators have studied posterior soft stabilization methods as an alternative to fusion. ${ }^{21-28}$ Four types of posterior soft stabilization devices have been introduced thus far: interspinous distraction devices, interspinous ligament devices, pedicle screw-based ligaments, and pedicle screwbased semimetallic devices. ${ }^{32}$ All of these have been used in the treatment of various spinal instabilities, including spinal stenosis, degenerative discopathy, huge disc herniation, and spondylolisthesis, and in revision surgery. Because the devices differ in design and biomechanical properties, the choice of device should differ according to clinical circumstances; however, a discussion of the applications, advantages, and disadvantages of each device is beyond the scope of this study.

The device we used was an interspinous ligament device without interspinous hard anchorage. Although there have been a few clinical studies using this ligament or a similar device, ${ }^{21,33,34}$ devices in this category have not been widely accepted in the spine community. We chose this device to provide subtle additional stability after decompression for patients with degenerative spondylolisthesis. Although the problem of the patient with degenerative spondylolisthesis is instability caused by degeneration of the disc and laxity of the joint ligaments, ${ }^{35}$ it was our conjecture that stability of the motion segment could be obtained by applying soft ligament around the spinous processes to give the patients' natural ligamentous structures, which had not been completely destroyed, some additional power. This conjecture was based on biomechanical studies in which devices similar to the LVR were used..$^{21,36}$ Those studies showed that interspinous ligamentous devices had a stabilizing effect in flexionextension and lateral bending of spinal motion segments.

Initially, the artificial intervertebral ligament was used only for elderly patients or patients who had significant medical problems that could make a prolonged operation risky. But 
when successful outcomes were achieved, we postulated that the artificial intervertebral ligament could be used in younger, more active patients without significant medical problems. The indications for soft stabilization were broadened and most cases of degenerative spondylolisthesis could be treated with it; conditions in which solid fixation rather than soft stabilization was definitely warranted included spondylolisthesis exceeding grade I and concomitant disc herniation necessitating discectomy.

In our study, the clinical outcome parameters of the soft stabilization group showed better tendencies than those of the PLIF group, but the differences were not statistically significant. This means that the clinical efficacy of soft stabilization with the artificial intervertebral ligament was at least equal to the efficacy of the instrumented interbody fusion in selected cases. As a surgical procedure, soft stabilization is simple and minimally invasive, since there is no time-consuming and risky surgical step such as pedicle screw insertion or interbody fusion. This was proven by the shortened operating time and reduced blood loss in the soft stabilization group as compared with the PLIF group. Degenerative spondylolisthesis is a disease of elderly people, who frequently have comorbidities that can make extensive surgery risky. Thus, ligamentoplasty with an artificial intervertebral ligament can be a good alternative to instrumented fusion for such patients.

Because the artificial intervertebral ligament used in this study has no hard interspinous anchoring device, its stabilizing power may be too weak to correct olisthesis. There was no significant difference between preoperative and postoperative percentage of slippage (Figure 4). This means that the ligament failed to correct olisthesis; it only prevented further slippage. However, in patients who already had advanced slippage, even the prevention of further slippage was not achieved. Three of 4 patients in the soft stabilization group who had had preoperative slippage of more than $20 \%$ showed progression of slippage after surgery. This means that soft stabilization in advanced spondylolisthesis, even though not reaching grade II, is not adequate. Therefore, ligamentoplasty is not recommended for patients who have slippage of more than $20 \%$.

There are some limitations to the present study. First, the study design was retrospective. Although the preoperative clinical and radiological parameters of the 2 groups were similar, it is possible that patient selection or selection of surgical procedure were biased in some way. Second, the number of patients in each group was too small. To determine the efficacy of any new device in treating a disease, a prospective randomized study with significant numbers of patients is needed. Therefore, a definitive conclusion about the efficacy of soft stabilization with an artificial ligament in grade I degenerative spondylolisthesis cannot be drawn from this study. Because avoidance of the late consequences of fusion is one of the purposes of soft stabilization, it is important to compare the incidence and

\section{Figure 4}

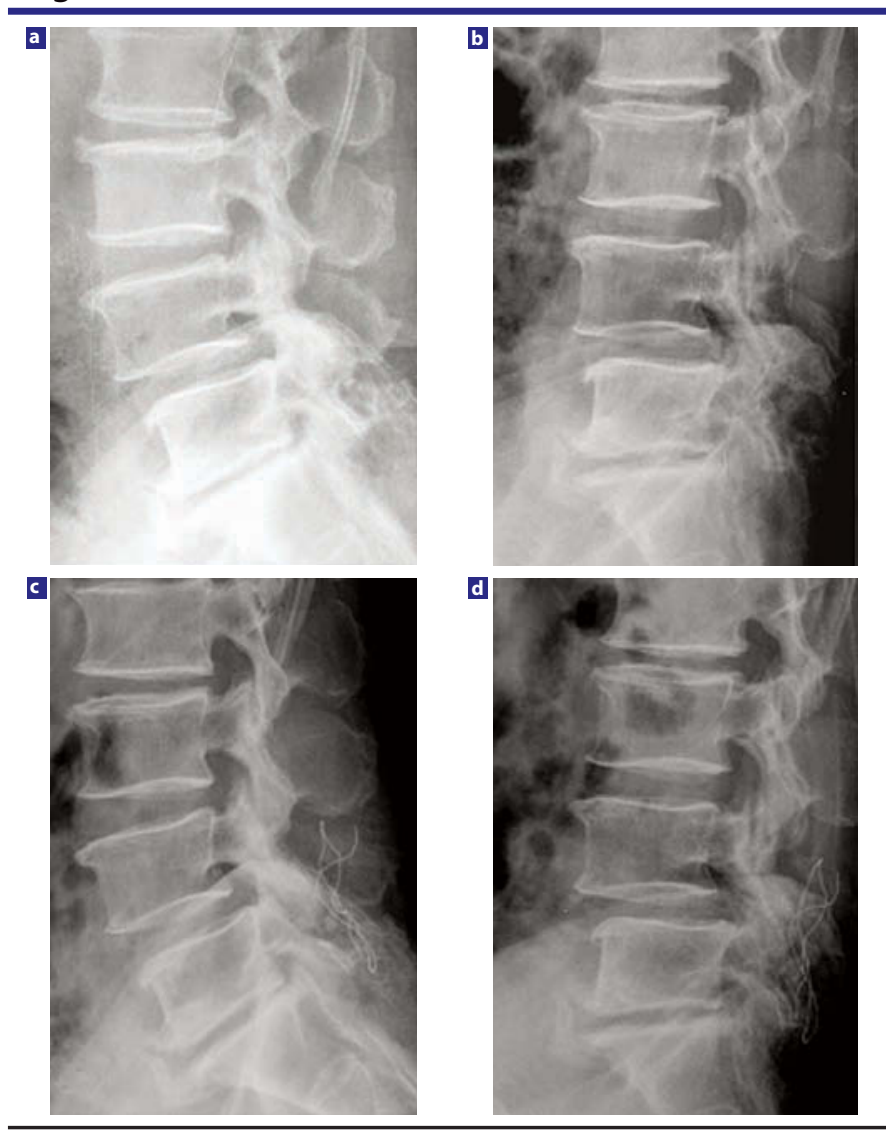

These x-rays are views from a 61-year-old man who underwent microdecompression and soft stabilization. Preoperative dynamic views $(a, b)$ of plain lateral radiograph showed grade I degenerative spondylolisthesis. Postoperative dynamic views (c, d) taken 2 years after surgery showed preserved segmental motion and no further progression of slippage.

severity of adjacent segment disease associated with each of the 2 stabilization procedures. However, since the follow-up period was too short to determine adjacent segment disease, it was not scrutinized in this study and remained as an issue that should be determined in a future study with prolonged follow-up periods.

In spite of these limitations, our results show that patients who underwent soft stabilization with an artificial intervertebral ligament did as well clinically as patients who underwent instrumented fusion, and they were more satisfied with their procedure. There was no serious side effect or significant failure of the soft stabilization procedure. Most important, the surgical time was shorter and bleeding was significantly less with soft stabilization than with fusion. In our opinion, if the patient is carefully selected, soft stabilization with an artificial ligament can be a good alternative to fusion for the treatment of grade I degenerative spondylolisthesis, especially in patients with significant comorbidities that increase the risk of prolonged and extensive surgery. 
Chan Shik Shim, MD, PhD, Sang-Ho Lee, MD, PhD, Sun-Hee Park, RN, CNS, and Ji-Hee Whang, MS

From the Department of Neurosurgery, Wooridul Spine Hospital, Seoul, South Korea.

The authors have no financial interest in relation to the device used in this study.

Address correspondence and reprint requests to Chan-Shik Shim, MD, PhD, Department of Neurosurgery, Wooridul Spine Hospital, 47-4 ChungdamDong, Gangnam-Gu, Seoul 135-100, Korea (email: shimcs@wooridul.co.kr, shimspine@hanmail.net).

This submission was received February 13, 2007 and accepted for publication June 15, 2007.

Protocol approval was not needed for this study, because it was a retrospective study.

This study was supported by a grant from the Wooridul Spine Foundation.

\section{REFERENCES}

1. Epstein NE. Decompression in the surgical management of degenerative spondylolisthesis: advantages of a conservative approach in 290 patients. J Spinal Disord. 1998;11:116-122.

2. Herron LD, Trippi AC. L4-5 Degenerative spondylolisthesis. The results of treatment by decompressive laminectomy without fusion. Spine. 1989;14:534-538.

3. Ito $\mathrm{Y}$, Oda H, Taguchi T, Inoue H, Kawai S. Results of surgical treatment for lumbar canal stenosis due to degenerative spondylolisthesis: enlargement of the lumbar spinal canal. J Orthop Sci. 2003;8:648-656.

4. Kristof RA, Aliashkevich AF, Schuster M, Meyer B, Urbach H, Schramm J. Degenerative lumbar spondylolisthesis-induced radicular compression: nonfusion-related decompression in selected patients without hypermobility on flexion-extension radiographs. J Neurosurg. 2002;97(3 suppl):281-286.

5. Herkowitz HN, Kurz LT. Degenerative lumbar spondylolisthesis with spinal stenosis: a prospective study comparing decompression with decompression and intertransverse process arthrodesis. J Bone Joint Surg Am. 1991;73:802-808.

6. Nork SE, Hu SS, Workman KL, Glazer PA, Bradford DS. Patient outcomes after decompression and instrumented posterior spinal fusion for degenerative spondylolisthesis. Spine. 1999;24:561-569.

7. Kinoshita T, Ohki I, Roth KR, Amano K, Moriya H. Results of degenerative spondylolisthesis treated with posterior decompression alone via a new surgical approach. J Neurosurg. 2001;95(1 suppl):11-16.

8. Bassewitz H, Herkowitz H. Lumbar stenosis with spondylolisthesis. Current concepts of surgical treatment. Clin Orthop Relat Res. 2001;384:54-60.

9. Bednar DA. Surgical management of lumbar degenerative spinal stenosis with spondylolisthesis via posterior reduction with minimal laminectomy. J Spinal Disord Tech. 2002;15:105-109.

10. Booth KC, Bridwell KH, Eisenberg BA, Baldus CR, Lenke LG. Minimum 5-year results of degenerative spondylolisthesis treated with decompression and instrumented posterior fusion. Spine. 1999;24:17211727.

11. Bridwell KH, Sedgewick TA, O'Brien MF, Lenke LG, Baldus C. The role of fusion and instrumentation in the treatment of degenerative spondylolisthesis with spinal stenosis. J Spinal Disord. 1993;6:461-472.
12. Fischgrund JS, Mackay M, Herkowitz HN, Browner R, Montgomery DM, Kurz LT. Degenerative lumbar spondylolisthesis with spinal stenosis: a prospective, randomized study comparing decompressive laminectomy and arthrodesis with and without spinal instrumentation. Spine. 1997;22:2807-2812.

13. Ghogawala Z, Benzel EC, Amin-Hanjani S, et al. Prospective outcomes evaluation after decompression with or without instrumented fusion for lumbar stenosis and degenerative grade I spondylolisthesis. J Neurosurg Spine. 2004;1:267-272.

14. Herkowitz HN. Spine update. Degenerative lumbar spondylolisthesis. Spine. 1995;20:1084-1090.

15. Mardjetko SM, Connolly PJ, Shott S. Degenerative lumbar spondylolisthesis: a meta-analysis of literature 1970-1993. Spine. 1994;19(20 suppl):2256S-2265S.

16. Deyo RA, Cherkin DC, Loeser JD, Bigos SJ, Ciol MA. Morbidity and mortality in association with operation on the lumbar spine. The influence of age, diagnosis, and procedure. J Bone Joint Surg Am. 1992;74:536543.

17. Lee CK. Accelerated degeneration of the segment adjacent to a lumbar fusion. Spine. 1998;13:375-377.

18. Lehmann TR, Spratt KF, Tozzi JE, et al. Long-term follow-up of lumbar fusion patients. Spine. 1987;12:97-104.

19. Park P, Garton HJ, Gala VC, Hoff JT, McGillicuddy JE. Adjacent segment disease after lumbar or lumbosacral fusion: review of the literature. Spine. 2004;29:1938-1944.

20. Schlegel JD, Smith JA, Schleusener RL. Lumbar motion segment pathology adjacent to thoracolumbar, lumbar, and lumbosacral fusion. Spine. 1996;21:970-981.

21. Caserta S, La Maida GA, Misaggi B, et al. Elastic stabilization alone or combined with rigid fusion in spinal surgery: a biomechanical study and clinical experience based on 82 cases. Eur Spine J. 2002;11(suppl 2):192-197.s

22. Garner MD, Wolfe SJ, Kuslich SD. Development and preclinical testing of a new tension-band device for the spine: the Loop system. Eur Spine J. 2002;11(suppl 2):186-191.

23. Kanayama M, Hashimoto T, Shigenobu K, Oha F, Ishida T, Yamane S. Non-fusion surgery for degenerative spondylolisthesis using artificial ligament stabilization: surgical indication and clinical results. Spine. 2005;30:588-592.

24. Konno S, Kikuchi S. Prospective study of surgical treatment of degenerative spondylolisthesis: comparison between decompression alone and decompression with Graf system stabilization. Spine. 2000;25:15331537.

25. Madan S, Boeree NR. Outcome of the Graf ligamentoplasty procedure compared with anterior lumbar interbody fusion with the Hartshill horseshoe cage. Eur Spine J. 2003;12:361-368.

26. Markwalder TM, Wenger M. Dynamic stabilization of lumbar motion segments by use of Graf's ligaments: results with an average follow-up of 7.4 years in 39 highly selected, consecutive patients. Acta Neurochir (Wien). 2003;145:209-214.

27. Sénégas J. Mechanical supplementation by non-rigid fixation in degenerative intervertebral lumbar segments: the Wallis system. Eur Spine J. 2002;11(suppl 2):164-169.

28. Stoll TM, Dubios G, Schwarzenbach O. The dynamic neutralization system for the spine: a multi-center study of a novel non-fusion system. Eur Spine J. 2002;11(suppl 2):170-178. 
29. Johnsson KE, Willner S, Johnsson K. Postoperative instability after decompression for lumbar spinal stenosis. Spine. 1986;11:107-110.

30. Fairbank JC, Pynsent PB. The Oswestry Disability Index. Spine. 2000;25:2940-2952.

31. McAfee PC, Boden SD, Brantigan JW, et al. Symposium: a critical discrepancy-a criteria of successful arthrodesis following interbody spinal fusion. Spine. 2001;26:320-334.

32. Sengupta DK. Dynamic stabilization devices in the treatment of low back pain. Orthop Clin North Am. 2004;35:43-56.

33. Lee SH, Chung BJ, Lee HY, Shin SW. A comparison between interspinous ligamentoplasty, posterior interbody fusion, and posterolateral fusion in the treatment of grade I degenerative lumbar spondylolisthesis. Joint Dis Rel Surg. 2005;16:111-117.

34. Lee SH, Lee IM, Sung KH, Sung YS, Kim JS. Comparison of posterior interbody fusion, posterolateral fusion, and interspinous ligamentoplasty for degenerative lumbar instability [abstract]. $J$ Neurosurg. 1997;86:424A.

35. Matsunaga S, Sakou T, Morizono Y, Masuda A, Demirtas M. Natural history of degenerative spondylolisthesis: pathogenesis and natural course of the slippage. Spine. 1990;15:1204-1210.

36. Voydeville G, Diop A, Lavaste F, Girard F, Hardy P. Experimental lumbar instability and artificial ligament. Eur J Orthop Surg Traumatol. 2000;10:167-176. 